\title{
PEN-3 Model Cultural Framework for Health Intervention and Prevention
}

\author{
Lisa Marie Portugal* \\ Department of Health and Wellness Education, Capella University, USA
}

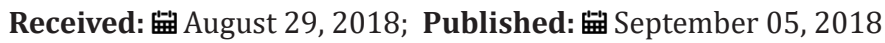

*Corresponding author: Lisa Marie Portugal, Department of Health and Wellness Education, Capella University, USA

\begin{abstract}
The PEN-3 Model Cultural Framework can be used to design culturally specific, locally relevant health intervention and prevention programs to educate communities. This health intervention and prevention involves educating Hispanic females and males between the ages of 15 to 32 . The health and wellness program design involve educating this group about the use of marijuana and its damaging effects on the body leading to mental illness, Diabetes, Cancer, lung and other organ damage, obesity, cognitive disorders, lowered IQ and EQ (emotional quotient), and various other damaging effects. Finally, a summary of the PEN-3 Model Cultural findings are discussed and analyzed to help health educators, practitioners, and advocates serve and address the needs of the target population.
\end{abstract}

\section{Introduction}

The PEN-3 cultural model can be used to assess marijuana use in the target population. The following components can identify themes in a practical approach to behavioral change through active participation: [1] cultural health behaviors, [2] data collection, [3] analysis, and [4] pattern recognition (Cowdery, Parker, \& Thompson, 2010; Melancon, Oomen-Early, \& del Rincon, 2009). The PEN-3 cultural model can be used as a qualitative and quantitative methodology heath assessment tool. PEN-3 assists health educators to actively engage the community through collaboration of health professionals with educational and scientific support [4,5].

\section{Objective}

Use a systematic approach to assess influences on the health behaviors of target populations. According to [6]. "Strategies that only emphasize individual change neglect an important aspect of ethnic populations, collectivism. Therefore, using more mainstream messages without addressing significant influences of the ethnic culture such as heritage, life experiences and cultural beliefs may act as a disincentive in disease prevention [7]. Focusing on cultural influences and the integration of cultural beliefs and experiences along with providing culturally sensitive messages by culturally competent educators may prove to be a more effective strategy for addressing minority health issues, particularly among minority populations". Health educators can focus on interventions that include the following components: (1) cultural understanding, (2) sensitivity, and (3) relevance.

\section{Pen-3 Model in Action}

a) Cultural Identity: Where to intervene? Who are the family members present in the lives of target population, in the home, and extended family relationships? What is the community, neighborhood, and environment like? What factors and people might be influencing the target population within the community,

b) Neighborhood, and environment?

c) Person: Hispanic population, females and males, between ages 15 to 32 years old.

d) Extended Family: Siblings, Aunts, Cousins, Mothers, Grandparents. 
e) Neighborhood: Environment and people who may have an influence on the target population.

Relationships and Expectations: Where to intervene? Who and where are negative influencing factors, people, and places that impact the views, perceptions, and ways of thinking of the target population? Who and where are positive influencing factors, people, and places that impact the views, perceptions, and ways of thinking of the target population? Compare and contrast conflicting messages from the environment, home, people, places, community, neighborhood, and family ties regarding marijuana use.

i. Perception: The affects/influence marijuana has on lungs, other organs, immune system, circulatory system, body, mind, spirit, Cancer, Diabetes, obesity, lower IQ and EQ cognitive thinking problems, and other health problems.

ii. Enablers: Health and wellness education support, resources, tools, access to correct information, access to naturopathy traditional medicine providers, and encouragement toward healthy choices. All forms of support from friends, family, community.

iii. Nurturer: Encourages education, knowledge-building from correct sources, people, providers, and naturopathy doctors / clinics in the area who are opposed to marijuana use. Encourage church and spiritual leaders' participation.

iv. Cultural Empowerment: Where to intervene? Is there a mindset to change positively toward healthy choices and the discontinuation of marijuana use? Are there aspects within the environment or culture that discourage healthy choices and promote or foster marijuana use? What beliefs or rituals might be present that prevent or promote healthy choices and the discontinuation of marijuana use?

v. Positive: Culturally promote attending religious services. Encourage spiritual health, spiritual education, spiritual warfare, and church leaders' participation in the agenda to stop marijuana use.

vi. Existential: Fostering positive cultural events, support systems messaging anti-drug use, drug use can lead to spiritual attack and mental illness.

vii. Negative: Encourage the target population and all associations to remove negative people, messages, and locations in environment that are unwilling to change / remove marijuana use.

\section{Methods}

This case study sought to understand the effects of culture, social norms, beliefs, values, ideology, and practices influencing health behaviors related to marijuana drug use in the target population. In addition, the researcher questioned participants about:

a) perceptions regarding marijuana, b) cultural and/or social taboos (if any) related to marijuana,

c) views regarding marijuana drug use by self or others, and

d) how much and how often self or others use marijuana.

The researcher randomly chose 15 families (nuclear and extended family members) to interview using qualitative questioning methods. The interviews were composed of a series of guided questions, were conducted in-person and by telephone, and were electronically audio-tape recorded. Transcription services were used to document the interviews to ensure accuracy.

\section{Results}

The diversity study revealed heavy marijuana abuse in the target population at all ages i.e. youth, adults, and elderly in the Boomer generations within most families. In addition, many family members viewed marijuana use as recreational similar to alcohol use. Although some family members expressed that marijuana use can be frowned upon within the family circles, and that marijuana use is an illegal drug, nonetheless, many stated they enjoy using. Some stated they know it is a problem in their lives, others stated they do not care if it is viewed as a problem, while others did not see a problem with their use whatsoever. Some also mentioned that marijuana use should be legalized. When asked if they were aware of mental, physical, and spiritual health problems associated with marijuana use, most were unaware. Some family members, i.e. more often the caretakers, mothers, grandmothers, grandfathers, and seniors past the Boomer generation did view marijuana use as negative and unhealthy. That was an important finding since patriarchal, matriarchal, and senior bonds are strong in Hispanic populations and viewed positively. With this information, health educators can gain insight into how to approach health education to influence health and wellness choices and motivating attitudes and behaviors toward change [8-13]. Most who use marijuana were clearly over-weight and/or obese, and when questioned about food consumption, most eat poorly (i.e. GMO foods, grocery store non-organic snacks, pre-made-boxed grocery store meals, fast food restaurants, low natural foods-vegetable diet, high processed sugar diet, high Glyphosate grains diet). Most, if not all family members questioned, were not aware of:

a) the GMO (genetically modified foods) crisis,

b) the Glyphosate crisis,

c) grocery store, non-organic foods crisis, and

d) the fast food restaurant fake-food crisis in Western nations.

Family members who do use marijuana, understood that "the munchies" typical of marijuana use (consumed with overeating), does add to their weight gain. But, none were aware of the food crisis in America and how overeating, in the areas mentioned, leads to Cancer, Diabetes, Lupus, dementia, Alzheimer's, and early 
death. This was another important finding where health educators can design culturally-targeted programs to address this lack of knowledge specifically and the tie-in with marijuana use.

\section{Summary of Findings}

The researcher's own experience and case study observations with this health challenge is that she has known many individuals throughout her life who have been negatively affected by marijuana use. Over time, she has witnessed their physical and mental health decline and illnesses manifest such as Cancer, Diabetes, Lupus, obesity, heart conditions, lung conditions, lowered IQ and EQ (emotional quotient), cognitive disabilities, mental illness, demonic possession, many other health problems, incarceration, destroyed relationships, and death. In fact, one cousin passed away recently and had all the conditions mentioned and he was a chronic marijuana abuser all his life. He passed away too early and too young in mid-2018. This is merely one example; the researcher has many more not discussed here. In addition, the researcher has witnessed the mental decline, severe mental illness, and demonic possession of many marijuana users over time as well. Although, marijuana is being touted as a "cure-all" for every health concern and illness these days, it does the complete opposite of all those claims. Whether the drug is used for smoking, religious purposes, marijuana essential oil, or eaten, all the effects are the same and not only damage the body physically, but also mentally and spiritually. There are many studies being faked today claiming marijuana oil is a cure-all or marijuana leaves can be used in food and smoothies as a cure-all as well. There is a nefarious shadow government agenda behind the marijuana push as "medicine." In addition, the wide-spread marijuana "medicinal" retail businesses opening on every street corner in Westernized societies today are part of this nefarious, shadow government agenda to push marijuana use on the public. The Hegelian Dialect here is that the government is against marijuana and "hiding" its medicinal properties from the public purposefully. Yet, the government is allowing these fake "medicinal" marijuana retail businesses are on every street corner in Westernized nations. This creates a dialectic in the minds of the public by allowing them to be socially engineered to believe "if the government is hiding marijuana as medicine, then I want to use marijuana more." If the government does not want people using marijuana and if they are "hiding" its medicinal use, then why does the government allow "medicinal" marijuana businesses on every street corner available for public use? That is how Hegelian Dialectic works. There is another claim that Hemp seeds cure Cancer. Many essential oils (astringents) have been used for centuries to cure Cancer and other illnesses. The purchase of essential oils is legal and does not require a government marijuana card that is used to list, document, and remove rights of citizens by the government. A government marijuana card is another Hegelian Dialectic requiring individuals to go to the government for cures, aid, and help. The government is not necessary in the detoxing of Cancer and other illnesses. That can be done by individuals without government intervention or the loss of civil gun rights as written into the U.S. Constitution. An illegal law was created in the U.S. to allow the government to confiscate one's gun rights if one has signed up for a government marijuana card. This is the encroachment and intrusion of nefarious government agents within the U.S.A. using the marijuana conversation as the Hegelian Dialectic tool to channel that agenda. Furthermore, a government marijuana card also lists and documents individuals as not having the proper mental capacity to care for oneself. This makes individuals easily subjectable to any government "intervention," vaccination, medical kidnapping, or imprisonment the government chooses to do to those documented and listed marijuana users.

The claim that Hemp seeds can cure Cancer and other illness might be valid as the use of essential oils, apricot seeds, peach seeds, and many other natural ingredients DO detox Cancer and many illnesses. But, the problem here is that the government, in cooperation with allopathic medicine, pharmaceutical companies, the Department of Agriculture, and Monsanto have been experimenting with GMO's (genetically modified foods and seeds) for a very long time. This information is published and easily assessable to the public if one chooses to look for it. Do you really trust getting Hemp seeds from these nefarious agents knowing that they genetically modify seeds and food? If one has to go to government agencies (and undercover agencies perpetrating nongovernment involvement such as the marijuana retail businesses) to purchase Hemp seeds (or Hemp seed oil), those seeds very well could be genetically modified with substances unknown dangerous, and toxic to the public. There are many ways to detox the body, mind, and spirit that are natural, healthy, and positive. Marijuana use, government intervention, marijuana "pots cards," allopathic medicine, pharmaceutical drugs, and secular psychiatric - psychological services are not the answer. There are many claims made in each of those nefarious Hegelian Dialectic areas - all are false. If individuals choose to believe marijuana can be used as medicine, go right ahead, they will experience most, if not all, of the health problems mentioned here as well as the legal issues discussed. Learning the hard way does unfortunately teach individuals through physical and mental illness, homelessness, destroyed family relationships, incarceration, civil rights confiscation, government intrusion, demonic possession, and death.

The job of health educators and practitioners is to reach those individuals who are willing to hear the truth. For those who want to follow the lies and remain in his or her ignorance, he or she will learn some very hard lessons in life going down that path. Hardheaded, insolent, naïve, uneducated individuals who willfully turn away from the truth learn very hard knocks in life. That is how we all learn - free-will. Do as one choose to his or her body and individuals all earn the logical conclusions to his or her choices in life. Finally, the comments and research expressed here have 
nothing to do with a moral judgment on individuals. The comments and assessments are made solely from knowledge, research, historical facts, and observational case study experiences. The researcher makes no moral judgments on what individuals choose to do. The researcher merely presents the facts, educates, and allows individuals his or her own free-will choices to make. When individuals decide to debate from a moral judgment perspective, the researcher passes as this study is not based on a moral judgment, but rather from a health assessment perspective rooted in facts, history, and case study experiences and observations. The message is not for individuals who want to challenge, justify, and rationalize their drug use. The message is for individuals who want to question and learn more about their unhealthy, dangerous habit or the habit of those they love. Likewise, the intention here is not to challenge or morally judge individuals who want to continue on in their drug use.

\section{Real Cancer Detox}

Cancer, Diabetes, Lupus, and all illness can be detoxed in many natural ways using natural foods, seeds, essential oils, more nonGMO organic plant food in diet, no processed sugar intake, no processed foods from the grocery store, no fast food restaurants, and many other ways not listed here, but easily researchable.

\section{Cancer protection}

When mice implanted with cells of a particularly deadly, fastgrowing human breast cancer were treated with the flavonoid apigenin, the cancerous growth slowed and the tumors shrank [11]. Apigenin may even be one reason why drinking chamomile tea has been found to reduce thyroid cancer risk by up to 80 percent. Interestingly, the compound was also found to bind to 160 proteins in the human body, which suggests it has far-reaching health effects [13]. Additionally, treatment of cells with apigenin or quercetin inhibits CD38 and promotes an increase in intracellular NAD+ levels. CD38 is the primary enzyme that lowers NAD+ levels, so by inhibiting it, NAD+ levels are increased [13]. Onions and garlic are also rich in flavonoids, including quercetin, which inhibits the growth of cancer cells. Unlike anthocyanins, which had no effect on lung function in smokers, quercetin has been shown to reduce the risk of lung cancer in smokers. It also reduces your risk of heart disease, lowers blood pressure, relieves symptoms of interstitial cystitis and reduces symptoms of prostatitis [13].

\section{How to Get More Flavonoids into Your Diet}

While this is certainly not an exhaustive list, to naturally increase the flavonoids in your diet, consider eating more of the following foods:

I. Flavanols: Onions, apples, kale, broccoli, garbanzo beans, almonds, turnip greens, sweet potatoes, quinoa

II. Flavan-3-ols: Apples, tea (including black, green, white and oolong), blueberries, peaches, pears, strawberries, cocoa
III. Flavones: Parsley, bell peppers, celery, apples, oranges, watermelon, chili peppers, cantaloupe, thyme

IV. Flavanones: Oranges, grapefruit, lemons, tomatoes

V. Anthocyanins: Strawberries, cherries, red cabbage, cranberries, plums, raspberries, blueberries, bilberries, black currants, purple grapes, purple potatoes

VI. Quercetin: Garlic, apples, plums, red grapes, citrus fruit, dark cherries and dark berries such as blueberries, blackberries and bilberries, capers, olive oil. Small amounts also found in parsley, sage, elder flower, gingko biloba and St. John's Wort

VII. Apigenin: Celery, parsley, thyme, basil, oregano, cilantro, chamomile, broccoli, leeks

VIII. Epicatechin: Cocoa, dark chocolate, apples, black grapes, blackberries, black tea, cherries (Mercola, 2018).

Whether or not you use a 'traditional' form of cancer treatment, there may be some foods that can help as well. More specifically, chemicals in the foods that can help. Dr. Patrick Quillin discusses these chemicals, where they can be found and how that can translate into benefits for our body.

\section{Explanation of what Health Educators can do to Collaborate with and Motivate the Population to Implement Behavioral Change}

Alcohol and drug abuse can have a devastating, lasting, and permanent negative impact on the wellbeing and health of youth [14]. Ultimately, ties should be cut with negative influencers, enablers, and the supply source - and if any signs are recognizable of unhealthy addictions, action should be taken immediately. Drug and alcohol abuse starts very early for most individuals who live in modern Westernized countries. Although drugs and alcohol have always been available throughout centuries, these substances are easily assessable to everyone, even children, in modern cultures. In older cultures, communities, and societies, drugs and alcohol were not as easily assessable and individuals were not bombarded everywhere with social messaging as they are in modern societies. Adults, children, and seniors can get access to drugs and alcohol everywhere and allopathic doctors regularly prescribe drugs to all groups as well. The opioid, anti-depressant, and psychotropic drugs epidemic is supported by allopathic doctors and pharmaceutical companies today. This problem is entrenched in all Westernized, modern societies today. Furthermore, many adults see nothing wrong with drinking alcohol heavily, prescription drugs, street drugs, and marijuana use. Many adults, seniors, and children are on these minds altering, mood altering, damaging, toxic, prescription drugs and the "prescription" gives individuals the notion that it is "ok." The prescription also gives individuals the fallacy that it is "medicine" because a doctor prescribed it. Many individuals and children are addicted junkies and they do not even know it or would not believe it if it was explained it to them. Westernized, 
modern populations live in an infused drug and alcohol society and individuals have been indoctrinated to believe their actions, choices, behaviors, and lifestyles are normal. The "make all drugs legal" conversion and the "make pot legal" conversation that never ends is especially designed to mind-control and mind-change values, morality, concept of health, and change how man views himself. These Hegelian Dialectic conversations in the public are not an accident or organic in any way. These conversations are always in the public sphere because nefarious government agents want those conversions in the public sphere. This is how those nefarious agents "change how man views man" or change how "man views himself." In other words, the purpose and agenda for this Hegelian Dialectic is to alter the views society has about drugs, alcohol, prescription drugs, street drugs, and marijuana use. The purpose is to make individuals feel more comfortable with believing it is ok and normal to use and abuse. THAT is the purpose of a Hegelian Dialectic conversation in the public sphere: (1) changing how man views himself; (2) changing man's traditional and cultural values and morality; (3) injecting new values and morality; and (4) giving individuals a rational, a justification for those new values. Most individuals in modern, Westernized societies do not even understand or recognize what real healthcare looks like. Most individuals have been so brainwashed and indoctrinated that they wholeheartedly believe in and have adopted these Hegelian Dialectic conversations and have zero understanding of real health and real healthcare. Finally, when individuals are questioned about the controlled ideas they have adopted into their thinking and lifestyle, they will: (1) debate it because it goes against their programming; (2) reject it because it goes against their programming (this is called Cognitive Dissonance); and (3) attack the messenger and the message because they cannot accept the opposite of what they have been programmed to believe all their lives. Teaching individuals how to live healthier with the truth is a high honor for health educators and practitioners and something they should strive to achieve...Truth and helping others.

\section{Tailor a Message about the Health Issue to the Target Population (Example)}

In a study conducted by Banning, Broeren, Joosten-van Zwanenburg, van As, van de Looij-Jansen, \& Raat, (2014), healthcare intervention messages specifically tailored for demographics (age, ethnicity, level of education, gender), can have a greater impact and effect on the target audience. This example message can be in Spanish and English or any language necessary to target other populations. Dear friends, loved ones, and my extended cultural community and family, Learn about the damaging effects of marijuana use that no one ever speaks about. Have you ever noticed those within your family and circle of friends who use marijuana might be experiencing many health problems such as Cancer, Diabetes, obesity, lethargy, just to name a few? If you have noticed some of these health problems, and other health problems, but never thought to tie-in the marijuana use before, start noticing. Do you know friends and family members who have been diagnosed with Cancer, Diabetes, and other health problems who also use marijuana? There is a connection that you may never have heard about before. Do you want to learn why people get physically ill and may also experience mental illness? Has it ever occurred to you that marijuana use leads to Cancer, Diabetes, obesity, mental illness, incarceration, destroyed family relationships, demonic possession, and death? If you have seen any of these problems in your family where marijuana use is present, would you be interested in learning more? Learn the tie-in with marijuana and illness and learn how to change a very damaging activity in your life or the lives of people you love. Why is this important? It could save your life or those you love. Share with your family and friends how you and they can learn to live a happier, healthier life, drug-free for yourself, children, and family today! "It is widely acknowledged that obesity is a serious health issue" and "the proportion of adults classified as overweight or obese is increasing steadily" [14]. In particular, research suggests that establishing family goals encourages working together to improve the lives of everyone within the family (11). In addition, an essential key to success when motivating family members is helping them reflect upon lifestyle choices and giving them educational tools to address ways in which they might make healthier decisions [14].

\section{Explanation of how Health Educators might help Target Population Adhere to and Sustain Health Behavioral Change Over Time}

Healthcare educators and practitioners can provide assistance in this area and create tools to educate families, parents, communities, and substance abusers about the issue from a research, case study, and teach by examples perspective. According to research by [13], "As suggested by medical research [12], family engagement plays an important role on health behaviour. A supportive environment within the family can promote behaviour change, helping, in particular, to achieve long-term goals" (p. 342). Involving and educating nuclear, extended, and communal family members is essential to the advocacy, buy-in, participation, promotion, and fostering of cultural behavioral change.

\section{Reflection on Behavioral Diversity}

Other health challenges society and all populations face today is how nurses, allopathic doctors, psychiatrists, and psychologists are part of the drug abuse in Western nations when they prescribe and administer psychotropic and anti-depressant drugs to children. This is an epidemic. Nurses, psychiatrists, and psychologists in public schools believe they are helping children when they buyinto the administering of these dangerous drugs to children in their care. Psychotropic and anti-depressant drugs are laced with heavy metals and other toxic, Cancer-causing agents that destroy the bodies and minds of children (adults too). These drugs are being 
administered to children in elementary, junior high, high school, and college when they are so-called "diagnosed" with the new fallacy in allopathic, psychiatric medicine called "depression." In fact, this is the latest con government agencies are pushing on populations in Westernized countries. Depression is not solved with drugs. It is solved in various other ways that involve diet, exercise, healthy living, fostering healthy child development, fostering healthy ego development, education, moral development, and the pursuit of virtue development versus pleasure or a quick drug fix. Psychotropic and anti-depressant drugs damage the mind, body, and spirit and these drugs do not heal or cure anything. In addition, these drugs do not address the underlying root cause of depression, but rather ignore the issue and merely drug children, adults, and seniors. Not only is the administering of these drugs malpractice, it is criminal. Furthermore, seniors and adults are being administered these drugs as well. Basically, anyone who visits an allopathic doctor or a hospital today will be prescribed these drugs. Individuals will also be given damaging, toxic, Cancer-causing vaccines with a hospital visit and many times against his or her knowledge, consent, and will. Follow nurses and damaged families and children speaking out about this issue on Vaxxed TV Figure 1.

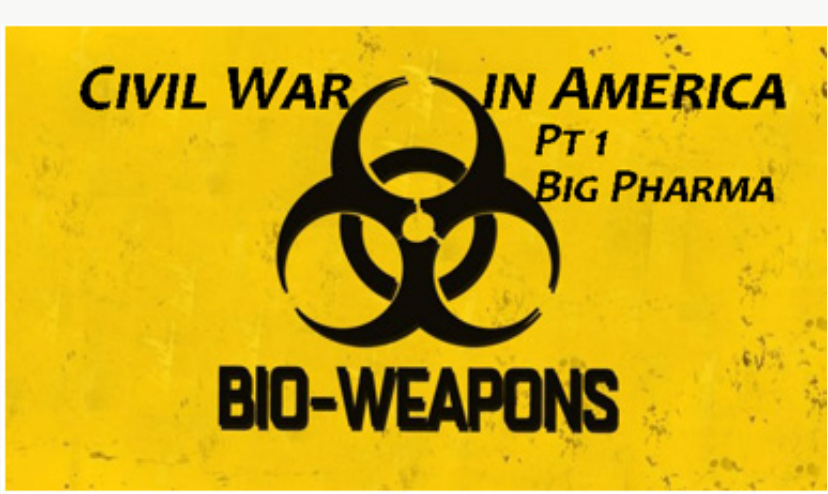

Figure 1: Pharmaceutical drugs and Vaccines = BioWeapons (12).

\section{Personal and Individualized Approaches to Health}

Health educators and practitioners can to take a personal and individualized approach to each case by helping communities find naturopathy traditional medicine sources, tools, research, doctors, and service providers in their local areas. In addition, counseling and education are crucial. Developing new health curriculum, programs, and services and reaching out to individuals where they are at is essential Health educators and practitioners can use technology; provide research, tools, and resources easily accessible to the public as well. Health educators and practitioners can write books, publish studies in peer-reviewed academic and medical journals, speak in public, speak in alternative media channels, develop websites, and get the message out into the public sphere. Health educators and practitioners can also be a resource within their families, spheres of influence, and communities.

\section{Bibliography Resources regarding the War on Citizens with Weaponized Drugs, Vaccines, and Indoctrination Warfare}

TheFetch, (2018, June 19). The raging civil war in America-pt 1The pharmaceutical terror wing. InsideTheEyeLive.com Retrieved from http://insidetheeyelive.com/the-raging-civil-war-in-americapt-1-the-pharmaceutical-terror-wing/ There is a civil war raging in America, it is just that nobody seems to see it, or even recognize how such might be so. The civil war is being waged on multiple fronts, but only one side seems to know it exists. Consequently, all the shots are being fired in one direction while those being targeted remain blissfully unaware that they are at war and that casualties are indeed being taken (12). There are those who are killed in action, wounded in action, and of course, missing in action (12). The civil war is relentless, yet nobody is shooting back. Perhaps it is because the people surviving the dying, caring for the maimed, and mourning the missing simply cannot fathom the nature of this raging civil war (12). In a very real way, paramilitary wings, secret death squads, air forces, and occupation propaganda outlets are all employed in this civil war, yet Americans blissfully seem to not notice (12). The Opioid Epidemic (12). Georgia Nurse gives Warning: Some Hospitals Mandating Flu Shot for Employees, or face Termination https://www.youtube.com/watch?v=9p0vAha6pZw OVER 22,000 U.S. NURSES REFUSE FLU SHOT! https://www. youtube.com/watch?v=c1c1akKIPuI Follow Vaxxed TV https:// www.youtube.com/channel/UCwZDSEpPvE3980LazdituKQ/ featured Veley, J. (2017, April 21). 14 Blatant lies about psychotropic drugs the FDA teaches medical students. NaturalNews.com Retrieved from https://www.naturalnews.com/2017-04-21-14blatant-lies-psychotropic-drugs-the-fda-teaches-medical-students. html Gutierrez, D. (2007, December 7).

Psychotropic Drug Prescriptions to Children Skyrocket 400 Percent in Ten Years. NaturalNews.com Retrieved from https:// www.naturalnews.com/022335_children_prescriptions_drugs. html Barendes, S. (2013, Novemer 25). Violence-A Side Effect of Psychotropic Drugs. NaturalNews.com Retrieved from https://www.naturalnewsblogs.com/violence-a-side-effect-ofpsychotropic-drugs/ Adams, M. (2013, April 5). Revealed: Aurora shooter James Holmes was taking prescription antidepressants and hypnosis drugs. NaturalNews.com Retrieved from

https://www.naturalnews.com/039796_james_holmes_ psychiatric_drugs_antidepressants.html Adams, M. (2009, November 7). Orlando shooter, US army Fort Hood shooter both linked to psychiatric drugs. NaturalNews.com Retrieved from https://www.naturalnews.com/027425_drugs_drugs_violence. html Fassa, P. (2012, March 1). How FDA and Big Pharma mislead millions into taking dangerous anti-depressants. NaturalNews. com Retrieved from https://www.naturalnews.com/035113_Big_ Pharma_FDA_anti-depressants.html. 


\section{Conclusion}

In conclusion, the PEN-3 Model Cultural Framework can be used to design culturally specific, locally relevant health intervention and prevention programs to educate communities. This health intervention and prevention involves educating Hispanic females and males between the ages of 15 to 32 . The health and wellness program design involve educating this group about the use of marijuana and its damaging effects on the body leading to mental illness, Diabetes, Cancer, lung and other organ damage, obesity, cognitive disorders, lowered IQ and EQ (emotional quotient), and various other damaging effects. Finally, a summary of the PEN-3 Model Cultural findings are discussed and analyzed to help health educators, practitioners, and advocates serve and address the needs of the target population.

\section{References}

1. Bannink R, Broeren S, Joosten-van Zwanenburg E, Van as E, van de Looij-Jansen P, et al. (2014) Use and appreciation of a web-based, tailored intervention (E-health4Uth) combined with counseling to promote adolescents' health in preventive youth health care: Survey and log-file analysis. JMIR Res Protoc 3(1): e3.

2. Colineau N, Paris C (2011) Motivating reflection about health within the family: The use of goal setting and tailored feedback. User Modeling \& User-Adapted Interaction 21(4-5): 341-376.

3. Coomer K (2014) What is the best approach to health promotion? Occupational Health 66(2): 17-19.
4. Cowdery JE, Parker S, Thompson A (2010) Application of the PEN-3 Model in a Diabetes prevention intervention. Journal of Health Disparities Research and Practice 4(1).

5. Downie RS, Tannahill C, Tannahill A (1996) Health Promotion: Models and values. Oxford: Oxford Medical Publications.

6. Ewles L, Simnett I (1999) Promoting health: A practical guide, (4 $4^{\text {th }}$ edn). Edinburgh: Ballière Tindall.

7. Karasek D, Ahern J, Galea S (2012) Social norms, collective efficacy, and smoking cessation in urban neighborhoods. Am J Public Health 102(2): 343-351.

8. Kemm J, Close A (1995) Health promotion: Theories and approaches. London, UK: Macmillan.

9. Melancon J, Oomen-Early J, del Rincon LM (2009) Using the PEN-3 Model to assess knowledge, attitudes, and beliefs about diabetes type 2 among Mexican American and Mexican Native men and women in North Texas. International Electronic Journal of Health Education 12: 203-221.

10. Mercola J (2018) The ultimate 'lung foods,' an important read if you're over 30 .

11. Naidoo J, Wills J (2000) Health promotion: Foundations for practice, $\left(2^{\text {nd }}\right.$ edn), Edinburgh: Ballière Tindall.

12. The Fetch (2018) The raging civil war in America- The pharmaceutical terror wing.

13. Thornton S (2015) Prevention and early detection of substance abuse is key. British Journal of School Nursing 10(6): 300-302.

14. Tones K, Tilford S (1994) Health Education: Effectiveness, efficiency and equity, $\left(2^{\text {nd }} \mathrm{edn}\right)$, London: Chapman \& Hall.

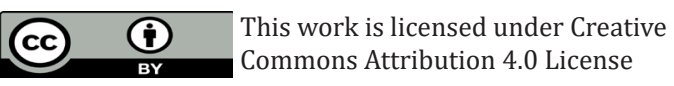

To Submit Your Article Click Here: Submit Article

DOI: $10.32474 / 0 J N B D .2018 .01 .000123$

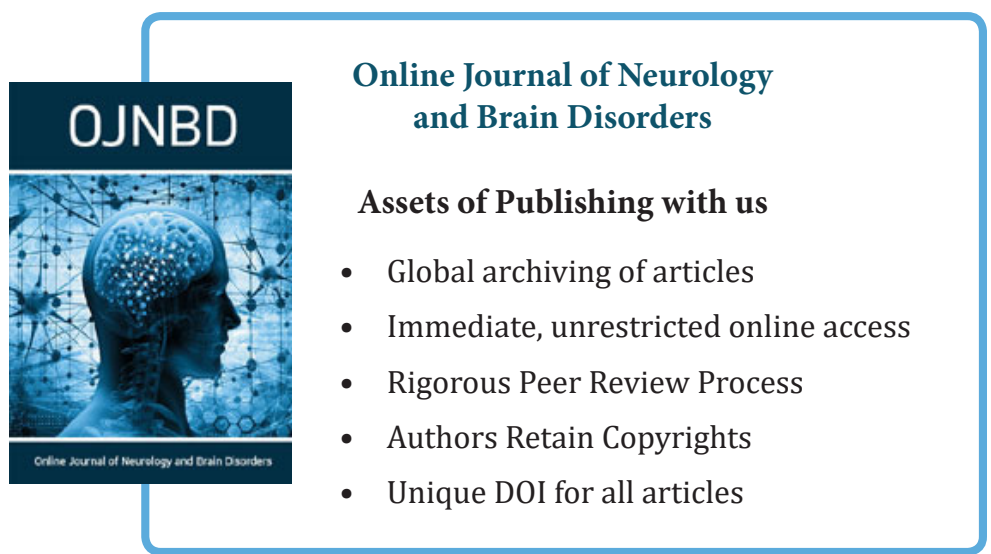

